\title{
Genetic Divergence Analysis in Muskmelon (Cucumis melo L.)
}

\section{B. Praveen Kumar Reddy ${ }^{1 *}$, Hameedunnisa Begum², Neelum Sunil ${ }^{3}$ and M. Thirupathi Reddy ${ }^{4}$}

\author{
${ }^{1}$ Department of Horticulture, College of Horticulture, \\ ${ }^{2}$ Vegetable Research Station, Dr. Y. S. R. Horticultural University, Rajendranagar, \\ Hyderabad-500030, Andhra Pradesh, India \\ ${ }^{3}$ National Bureau of Plant Genetic Resources Regional Station, Rajendranagar, \\ Hyderabad-500030, Andhra Pradesh, India \\ *Corresponding author
}

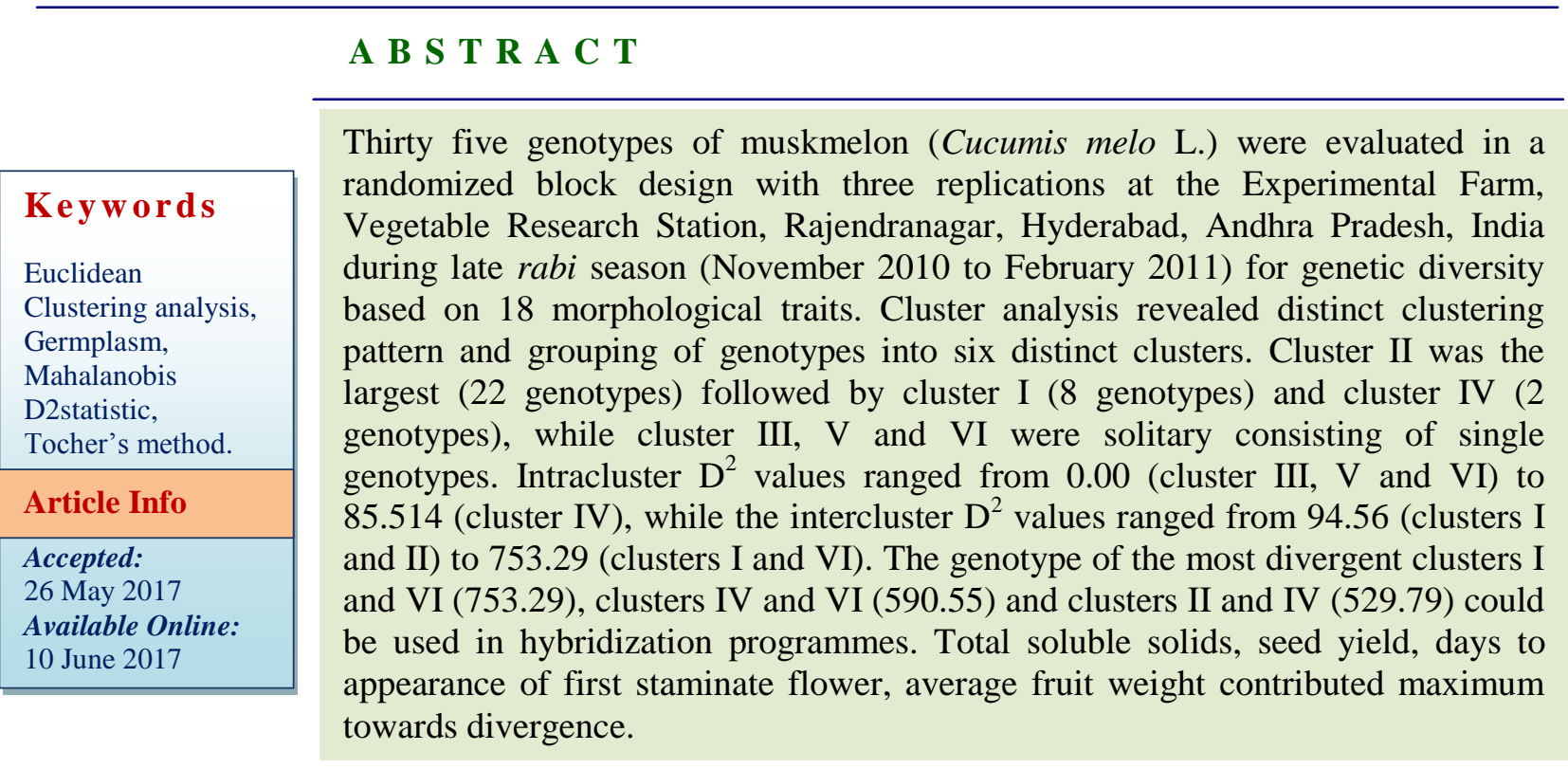

\section{Introduction}

Muskmelon (Cucumis melo L.) also known as cantaloupe is the most polymorphic species of the cucurbitaceae family, which is particularly true for fruit-related traits (Luan et al., 2010). It is likely originated in Asia from India to Persia, with their center of development near present day Iran. It is grown as a fruit vegetable almost worldwide from tropical to sub-tropical regions. It is a warm-season crop and thus tender and warmth loving.
It achieves prime quality when grown under warm and sunny conditions, but results in melons with inferior quality under cool and cloudy weather. It prefers sandy and sandy loam soils. In India, it is grown in both garden lands and riverbeds. In Andhra Pradesh (India), muskmelons are cultivated in riverbeds prominently in Kadapa and sparsely in Nellore and Kurnool districts. Its fruits are used as dessert and also eaten alone. It is highly relished because of its flavor, sweet 
taste and refreshing effect. It is a good source of dietary fiber, vitamins and minerals. It fetches premium price in the market compared to other fruit vegetables. It is gaining lot of importance due to its medium duration and high production potential as well as its high nutritive, medicinal and industrial value. In spite of its multiple virtues, its productivity is very low as compared to other fruit vegetables in India. In addition to other production constraints, lack of advanced varieties has contributed to the low productivity and quality of muskmelon in India. High yield can be achieved by improving cultural practices and by developing genetically superior cultivars. As muskmelon production is gaining importance at domestic and international level, mining into new germplasm lines and their systematic study is a prerequisite to develop new advanced or hybrid varieties which can withhold the challenges of both quantity and quality aspects on commercial lines.

For the breeding of muskmelon, germplasm is available including from accessions collected on small farms to hybrids developed by seed companies, representing a source of numerous possible crosses to generate lines. Information on genetic divergence among the available germplasm is vital to a plant breeder for an efficient choice of parents for hybridization. In this context, one key aspect is the choice of parents for the breeding of improved lines, since the improvement process is long. Erroneously chosen parents would, therefore, result in no profit, but in a waste of time and resources. There is a great potential in improving the productivity potential of vegetable crops by using suitable parents through hybridization programme. It was also observed that the more diverse the parents, greater are the chances ofobtaining high heterotic $\mathrm{F}_{1} \mathrm{~s}$ and broad spectrum of variability in the segregating generation (Arunachalam, 1981). However, only limited information is available on intraspecific genetic diversity and relationships within muskmelon germplasm collections. The germplasm of muskmelon also has not been well characterized from the point of view of its exploitation for the improvement of yield in general, and fruit quality in particular. Further, there is an increased interest for a meaningful understanding of the germplasm of the muskmelon and the extent of their genetic diversity.

Multivariate analysis following Mahalanobis $\mathrm{D}^{2}$ statistics (Mahalanobis, 1936) has been used to quantify the genetic divergence between the genotypes and to identify diverse parents for hybridization. This technique has been employed widely to resolve divergence at inter varietal, species and subspecies levels in classifying problems in crop plants (FAO, 1997). Although Mahalanobis $D^{2}$ statistics is a quantitative measure of genetic divergence, yet the clustering pattern of the genotypes is arbitrary. Though genetically diverse parents yield maximum heterosis, the magnitude of divergence critically matters the $\mathrm{F}_{1}$ heterosis. This technique, therefore, deserves to be tested on a wide range of crops (Joshi and Dhawan, 1966). Multivariate analysis following Mahalanobis $D^{2}$ statistics revealed rich genetic diversity for various growth, earliness and yield associated traits in the germplasm offering a great scope for improvement of muskmelon (Singh and Lal, 2000; More and Seshadri, 2002; Choudhary and Ram, 2003; Krishnaprasad et al., 2004; Yadav et al., 2005; Singh and Dhillon, 2006; Musmadeet al., 2008; Tomar et al., 2008; Rad et al., 2010).

Its genetic diversity has been utilized in various breeding programmes, which resulted in the development and release of a good number of varieties in muskmelon. However, the released varieties cannot be continued longer due to genetic drift and susceptibility 
to various pests and diseases. This demands replacement of current varieties by new varieties. The aim of our study was to evaluate the nature and extent of genetic diversity among the genotypes of muskmelon using Euclidean clustering analysis to identify promising genotypes, which can be used in different genetic improvement programmes of this crop. This study is important in the view that germplasm lines have their wide varied origin and are highly variable with respect to growth, earliness and fruit morphological aspects.

\section{Materials and Methods}

The experimental material comprised of 35 genotypes of muskmelon. Genotypes were evaluated in a randomized block design with three replications at the Experimental Farm, Vegetable Research Station, Rajendranagar, Hyderabad, Andhra Pradesh, India. The study was done in the late rabi season (November 2010 to February 2011). Each genotype was grown in a single-row plot of 3.6 length and $2.0 \mathrm{~m}$ width. Rows were spaced $2.0 \mathrm{~m}$ apart, while plants were spaced $0.60 \mathrm{~m}$ apart accommodating six plants in row. Seeds were initially sown in plug trays in the nursery in the first week of November 2011 and 25 days old seedlings were transplanted in the main field in the first week of December, 2011. The observations were recorded on five randomly selected plants from each genotype in each replication for vine length $(\mathrm{cm})$, number of primary branches per vine, fruit length $(\mathrm{cm})$, fruit diameter $(\mathrm{cm})$, average fruit weight $(\mathrm{g})$, number of fruits per vine, fruit cavity length $(\mathrm{cm})$, fruit cavity width $(\mathrm{cm})$, rind thickness $(\mathrm{mm})$, pulp thickness $(\mathrm{cm})$, total soluble solids ( ${ }^{\circ}$ Brix), seed yield (g/fruit), fruit yield (kg/plant) except days to appearance of first staminate flower, days to appearance of first pistillate flower, node number of first pistillate flower, days to first fruit harvest, days to last fruit harvest and total yield per plant $(\mathrm{g})$, which were recorded on whole plot basis. Genetic divergence between genotypes was worked out using Mahalanobis $\mathrm{D}^{2}$ statistics (Mahalanobis, 1936). The clustering of genotypes was done following Tocher's method as described by Rao (1952). The average intra and inter cluster distances were calculated by the formula given by Singh and Chaudhary (1985). The character contribution towards genetic divergence was computed using method given by Singh and Chaudhary (1985).

\section{Results and Discussion}

\section{Analysis of dispersion}

The simultaneous significance of mean differences was tested by analysis of dispersion (data not shown). The F-value is highly significant indicating large differences between the means of the populations based on pooled effect of all the eighteen characters and may be continued for further analysis for computing $\mathrm{D}^{2}$ estimates.

\section{Clustering pattern}

Based on $\mathrm{D}^{2}$ values, 35 genotypes were grouped into six highly divergent clusters (Table 1). Among six clusters, cluster II was the largest consisting of 22 genotypes followed by cluster I (8 genotypes) and cluster IV (2 genotypes). Cluster III, V and VI were solitary with only one genotype.

\section{Intracluster and intercluster distances}

The mean intra and inter cluster $\mathrm{D}^{2}$ values among the six clusters are given in table 2 . The intracluster $\mathrm{D}^{2}$ value ranged from 0.00 (Cluster III, V and VI) to 85.51 (Cluster IV). The cluster IV had the maximum intracluster distance (85.51) followed by cluster I (68.31) and cluster II (60.53). The intercluster $\mathrm{D}^{2}$ values among the six clusters ranged from 
94.56 to 753.29 . The intercluster distance was highest between clusters I and cluster VI (753.29), followed by cluster IV and VI (590.55) and cluster II and cluster VI (529.79). The intercluster distance was lowest between clusters I and cluster II (94.56), followed by cluster II and cluster IV (169.75) and cluster II and cluster III (185.34).

\section{Cluster means}

The cluster means for the eighteen characters studied in muskmelon genotypes revealed considerable differences among all the clusters (Table 3). Vine length was highest in cluster V $(109.73 \mathrm{~cm})$, followed by cluster III $(94.87 \mathrm{~cm})$ and cluster II $(80.26 \mathrm{~cm})$, while lowest in cluster VI $(75.60 \mathrm{~cm})$ followed by cluster IV $(78.07 \mathrm{~cm})$ and cluster I (80.16 $\mathrm{cm})$. Maximum number of primary branches per vine was recorded in cluster VI (4.20) followed by cluster III (3.47) and cluster IV (3.20), whereas minimum number of primary branches per vine was recorded in cluster I (2.73) followed by cluster II (3.05) and cluster $\mathrm{V}$ (3.07).

The genotypes of cluster III had the minimum days to appearance of first staminate flower (35.07), followed by cluster V (35.27) and cluster VI (40.93), whereas the genotypes of cluster II had the maximum days to appearance of first staminate flower (47.32) followed by cluster I (45.63) and cluster IV (44.03). With regard to days to appearance of first pistillate flower, the genotypes of cluster $\mathrm{V}$ had minimum mean value (54.73), followed by cluster III (55.00) and cluster VI (55.93), while cluster I had maximum mean value (58.56), followed by cluster II (58.38) and cluster IV (57.20). The cluster VI had the lowest node number of first pistillate flower (4.47), followed by cluster II (4.48) and cluster V (4.53), whereas cluster I had the highest node number of first pistillate flower (4.95), followed by cluster IV (4.63) and cluster III (4.60). Days to first fruit harvest was lowest in cluster III (78.67), followed by cluster V (80.67) and clusters VI (82.27), while highest in cluster I (89.39) followed by cluster II (87.29) and cluster IV (87.20). Days to last fruit harvest was maximum in cluster I (109.52) followed by cluster II (107.59) and cluster IV (107.33), while minimum in cluster III (97.00 days) followed by cluster VI (98.07) and cluster V (99.27). The genotypes of cluster $\mathrm{V}$ had maximum fruit length (16.33 $\mathrm{cm})$ followed by cluster VI $(16.00 \mathrm{~cm})$ and cluster IV $(11.05 \mathrm{~cm})$, whereas the genotypes of cluster I had minimum fruit length (8.91 $\mathrm{cm})$ followed by cluster III $(8.95 \mathrm{~cm})$ and cluster II $(10.90 \mathrm{~cm})$. Fruit diameter was highest in cluster III $(10.89 \mathrm{~cm})$ followed by cluster VI $(9.15 \mathrm{~cm})$ and cluster IV $(8.79 \mathrm{~cm})$, while lowest in cluster $\mathrm{V}(7.38 \mathrm{~cm})$ followed by cluster I $(8.10 \mathrm{~cm})$ and cluster II $(8.62 \mathrm{~cm})$. Average fruit weight was maximum in cluster VI (772.33 g) followed by cluster III (520.00 g) and cluster IV (461.67 g), while minimum in cluster I ( $297.50 \mathrm{~g})$ followed by cluster III (433.99 g) and cluster V (436.67 g). Number of fruits per vine was maximum in cluster $\mathrm{V}$ (3.40) followed by cluster I (2.83) and cluster II (2.82), while minimum in cluster VI (2.20) followed by cluster III (2.33) and cluster IV (2.73).

Fruit cavity length was highest in cluster V $(13.10 \mathrm{~cm})$ followed by cluster VI $(10.83 \mathrm{~cm})$ and cluster IV $(6.47 \mathrm{~cm})$, while lowest in cluster I $(5.07 \mathrm{~cm})$ followed by cluster III $(6.03 \mathrm{~cm})$ and cluster II $(6.17 \mathrm{~cm})$. Fruit cavity width was maximum in cluster III $(6.53 \mathrm{~cm})$ followed by cluster VI $(6.00 \mathrm{~cm})$ and cluster IV $(4.74 \mathrm{~cm})$, while minimum in cluster V $(3.70 \mathrm{~cm})$ followed by cluster II $(4.66 \mathrm{~cm})$ and cluster I $(4.32 \mathrm{~cm})$. Rind thickness was highest in cluster III $(2.57 \mathrm{~mm})$ followed by cluster IV $(2.45 \mathrm{~mm})$ and cluster VI $(2.13 \mathrm{~mm})$, while lowest in cluster I (1.41 $\mathrm{mm})$ followed by cluster $\mathrm{V}(1.43 \mathrm{~mm})$ and cluster II $(1.69 \mathrm{~mm})$. Pulp thickness was 
highest in cluster III $(1.89 \mathrm{~cm})$ followed by cluster IV $(1.76 \mathrm{~cm})$ and cluster II $(1.59 \mathrm{~cm})$, whereas lowest in cluster $\mathrm{V}(0.97 \mathrm{~cm})$ followed by cluster VI $(1.43 \mathrm{~cm})$ and cluster I $(1.56 \mathrm{~cm})$. Total soluble solids were lowest in cluster III $\left(6.00{ }^{\circ}\right.$ Brix $)$ followed by cluster $\mathrm{V}$ $\left(6.10^{\circ} \mathrm{Brix}\right)$ and cluster VI $\left(6.22^{\circ} \mathrm{Brix}\right)$, while highest in cluster IV (9.03 ${ }^{\circ}$ Brix) followed by cluster II $\left(6.68{ }^{\circ}\right.$ Brix $)$ and cluster I (6.41 ${ }^{\circ}$ Brix). Seed yield per fruit was minimum in cluster I and II ( $3.97 \mathrm{~g})$ followed by cluster IV $(4.34 \mathrm{~g})$, whereas maximum in cluster VI $(6.90 \mathrm{~g})$ followed by cluster III $(5.31 \mathrm{~g})$ and cluster V $(5.00 \mathrm{~g})$. Fruit yield per vine was highest in cluster VI $(1.70 \mathrm{~kg})$ followed by cluster V $(1.49 \mathrm{~kg})$ and cluster IV $(1.26 \mathrm{~kg})$, while lowest in cluster I $(0.84 \mathrm{~kg})$ followed by cluster II and cluster III (1.22 kg).

\section{Percent contribution of individual characters to diversity}

The percent contribution of each character towards divergence is presented in table 4. It was observed that total soluble solids contributed maximum (19.16\%) towards divergence followed by seed yield (15.29\%), days to appearance of first staminate flower
(14.12\%), average fruit weight (12.94\%), fruit cavity length (10.92\%), fruit length (7.23\%), fruit cavity width $(6.05 \%)$, rind thickness $(5.88 \%)$, node number of first pistillate flower (4.54\%), number of primary branches per vine $(2.18 \%)$, pulp thickness $(1.01 \%)$ and fruit yield $(0.67 \%)$. In contrast, fruit yield had contributed least $(0.67 \%)$. However, the remaining characters such as plant height, days to appearance of first pistillate flower, days to first fruit harvest, days to last fruit harvest, fruit diameter and number of fruits per vine did not contribute materially towards total diversity.

Earlier muskmelon was a minor dessert fruit, but at present it become a major dessert fruit in the country due to availability of exotic open pollinated/hybrid varieties in the market. Due to its Asian origin from India to Persia, with their center of development near what is Iran today and related domestication history, muskmelon has several landraces over ages. Traditional muskmelon landraces still extant in different ecosystems may provide the genetic diversity needed to diversify the depauperate gene pool of improved muskmelon varieties.

Table.1 Clustering pattern of 35 genotypes for eighteen growth, earliness and fruit yield attributes of muskmelon

\begin{tabular}{|l|c|l|}
\hline Cluster & $\begin{array}{c}\text { No. of } \\
\text { genotypes }\end{array}$ & Genotypes \\
\hline I & 8 & $\begin{array}{l}\text { RNMM-14, RNMM-25, RNMM-18, RNMM-30, RNMM-4, } \\
\text { RNMM-15, RNMM-16, RNMM-24 }\end{array}$ \\
\hline II & 22 & $\begin{array}{l}\text { RNMM-17, RNMM-5, RNMM-23, RNMM-6, RNMM-19, } \\
\text { RNMM-21, RNMM-26, RNMM-1, RNMM-29, RNMM-33, } \\
\text { RNMM-11, RNMM-2, RNMM-34, RNMM-8, RNMM-10, } \\
\text { RNMM-22, RNMM-20, RNMM-35, RNMM-13, RNMM-27, } \\
\text { RNMM-9, RNMM-7 }\end{array}$ \\
\hline III & 1 & RNMM-31 \\
\hline IV & 2 & RNMM-28, RNMM-12 \\
\hline V & 1 & RNMM-32 \\
\hline VI & 1 & RNMM-3 \\
\hline
\end{tabular}


Table.2 Average intra (bold) and inter-cluster $\mathrm{D}^{2}$ values for six clusters in 35 genotypes of muskmelon

\begin{tabular}{|l|l|l|l|l|l|l|}
\hline Clusters & I & II & III & IV & V & VI \\
\hline I & $\mathbf{6 8 . 3 0 9}$ & 94.559 & 233.801 & 254.224 & 474.661 & 753.294 \\
\hline II & & $\mathbf{6 0 . 5 3 1}$ & 185.343 & 169.751 & 351.026 & 529.794 \\
\hline III & & & $\mathbf{0}$ & 304.462 & 354.054 & 345.664 \\
\hline IV & & & & $\mathbf{8 5 . 5 1 4}$ & 480.994 & 590.547 \\
\hline V & & & & & $\mathbf{0}$ & 275.004 \\
\hline VI & & & & & & $\mathbf{0 . 0 0 0}$ \\
\hline
\end{tabular}

Table.3 Mean values of clusters for eighteen growth and fruit yield attributes in 35 genotypes of muskmelon

\begin{tabular}{|l|l|l|l|l|l|l|}
\hline \multirow{2}{*}{ Character } & \multicolumn{5}{l}{ Cluster } & \multicolumn{5}{ll}{} \\
\cline { 2 - 7 } & I II & III & IV & V & VI \\
\hline Vine length (cm) & 80.16 & 80.26 & 94.87 & 78.07 & 109.73 & 75.60 \\
\hline $\begin{array}{l}\text { Number of primary } \\
\text { branches per vine }\end{array}$ & 2.73 & 3.05 & 3.47 & 3.20 & 3.07 & 4.20 \\
\hline $\begin{array}{l}\text { Days to appearance of } \\
\text { first staminate flower }\end{array}$ & 45.63 & 47.32 & 35.07 & 44.03 & 35.27 & 40.93 \\
\hline $\begin{array}{l}\text { Days to appearance of } \\
\text { first pistillate flower }\end{array}$ & 58.56 & 58.38 & 55.00 & 57.20 & 54.73 & 55.93 \\
\hline $\begin{array}{l}\text { Node number of first } \\
\text { pistillate flower }\end{array}$ & 4.95 & 4.48 & 4.60 & 4.63 & 4.53 & 4.47 \\
\hline Days to first fruit harvest & 89.39 & 87.29 & 78.67 & 87.20 & 80.67 & 82.27 \\
\hline Days to last fruit harvest & 109.53 & 107.59 & 97.00 & 107.33 & 99.27 & 98.07 \\
\hline Fruit length (cm) & 8.91 & 10.90 & 8.95 & 11.05 & 16.33 & 16.00 \\
\hline Fruit diameter (cm) & 8.10 & 8.62 & 10.89 & 8.79 & 7.38 & 9.15 \\
\hline Average fruit weight (g) & 297.50 & 433.99 & 520.00 & 461.67 & 436.67 & 772.33 \\
\hline Number of fruits per vine & 2.83 & 2.82 & 2.33 & 2.73 & 3.40 & 2.20 \\
\hline Fruit cavity length (cm) & 5.07 & 6.17 & 6.03 & 6.47 & 13.10 & 10.83 \\
\hline Fruit cavity width (cm) & 4.32 & 4.66 & 6.53 & 4.74 & 3.70 & 6.00 \\
\hline Rind thickness (mm) & 1.41 & 1.69 & 2.57 & 2.45 & 1.43 & 2.13 \\
\hline Pulp thickness (cm) & 1.56 & 1.59 & 1.89 & 1.76 & 0.97 & 1.43 \\
\hline TSS ( ${ }^{\circ}$ Brix) & 6.41 & 6.68 & 6.00 & 9.03 & 6.10 & 6.22 \\
\hline Seed yield (g/fruit) & 3.97 & 3.97 & 5.31 & 4.34 & 5.00 & 6.90 \\
\hline Fruit yield (kg/plant) & 0.84 & 1.22 & 1.22 & 1.26 & 1.49 & 1.70 \\
\hline
\end{tabular}


Table.4 Per cent contribution of eighteen quantitative characters towards diversity in 35 genotypes of muskmelon

\begin{tabular}{|l|l|c|c|}
\hline S. No. & Character & Times ranked 1 & $\begin{array}{c}\text { Per cent } \\
\text { contribution }\end{array}$ \\
\hline 1 & Vine length (cm) & 0 & 0.00 \\
\hline 2 & $\begin{array}{l}\text { Number of primary branches } \\
\text { per vine }\end{array}$ & 13 & 2.18 \\
\hline 3 & $\begin{array}{l}\text { Days to appearance of first } \\
\text { staminate flower }\end{array}$ & 84 & 14.12 \\
\hline 4 & $\begin{array}{l}\text { Days to appearance of first } \\
\text { pistillate flower }\end{array}$ & 0 & 0.00 \\
\hline 5 & $\begin{array}{l}\text { Node number of first pistillate } \\
\text { flower }\end{array}$ & 27 & 4.54 \\
\hline 6 & Days to first fruit harvest & 0 & 0.00 \\
\hline 7 & Days to last fruit harvest & 0 & 0.00 \\
\hline 8 & Fruit length (cm) & 43 & 7.23 \\
\hline 9 & Fruit diameter (cm) & 0 & 0.00 \\
\hline 10 & Average fruit weight (g) & 77 & 12.94 \\
\hline 11 & Number of fruits per vine & 0 & 0.00 \\
\hline 12 & Fruit cavity length (cm) & 36 & 10.92 \\
\hline 13 & Fruit cavity width (cm) & 35 & 6.05 \\
\hline 14 & Rind thickness (mm) & 6 & 5.88 \\
\hline 15 & Pulp thickness (cm) & 91 & 1.01 \\
\hline 16 & TSS ( ${ }^{\circ}$ Brix) & 4 & 19.16 \\
\hline 17 & Seed yield (g/fruit) & 0.67 \\
\hline 18 & Fruit yield (kg/plant) & 0.29 \\
\hline & & & 0.00 \\
\hline
\end{tabular}

Owing to their adaptation to a wide range of agro-ecological conditions, traditional land races represent tremendous genetic diversity not found in modern cultivars. These landraces can, therefore, be exploited to significantly enhance muskmelon productivity. Explorations of muskmelon in the center of origin permit major advances in the characterization of its diversity. In parallel, ex situ plant conservation initiatives bloomed, ensuring the collection and conservation of landraces through development of seed banks. Thus, unraveling the genetic potential of muskmelon's land races for breeding purpose emerged.

One of the primary needs of the muskmelon crop industry is the estimation of genetic diversity between land races for identification and breeding purposes. Improving crops, however, requires reserves of genetic materials whose evaluation, conservation, management and use have barely begun to receive the attention that they deserve. Improvement in yield and quality is normally achieved by selecting genotypes with desirable character combinations existing in the nature or by hybridization. Selection of parents identified on the basis of divergence analysis would be more promising for a hybridization programme. Comprehensive information of the nature and magnitude of genetic divergence of the genotypes is the prerequisite of a variety development programme. The importance of genetic diversity in any crop improvement programme has been stressed both in self and cross-pollinated crops. The quantification of 
genetic diversity through biometrical procedures has made it possible to choose genetically diverge parents for a successful hybridization programme. Multivariate analysis by means of Mahalanobis $\mathrm{D}^{2}$ statistics is an useful tool in quantifying the degree of genotypic divergence among biological populations and to assess the relative contribution of different components to the total divergence both at inter and intracluster levels. The $\mathrm{D}^{2}$ statistics helps in selecting desirable parents for achieving desired goal by the breeder. In the present study, Euclidean cluster method facilitated grouping the 35 germplasm lines into six clusters based on $\mathrm{D}^{2}$ distances. The magnitude of $\mathrm{D}^{2}$ values confirmed that there was considerable and substantial amount of diversity in the among 35 germplasm lines included in the present study for all the eighteen characters under consideration collectively. Several authors also reported profound diversity in the germplasm of muskmelon by assessing genetic divergence on the basis of quantitative traits following Mahalanobis D ${ }^{2}$ statistics (Singh and Lal, 2000; More and Seshadri, 2002; Choudhary and Ram, 2003; Krishnaprasad et al., 2004; Yadav et al., 2005; Singh and Dhillon, 2006; Musmade et al., 2008; Tomar et al., 2008; Rad et al., 2010). Murthy and Arunachalam (1960) pointed that Mahalanobis $\mathrm{D}^{2}$ statistics is an important breeding tool to evaluate the clustering pattern.

Average intercluster and intracluster distances revealed that, in general, intercluster distances were much higher than those of intracluster distances, suggesting homogeneous and heterogeneous nature of the germplasm lines within and between the clusters, respectively. These results are in accordance with the findings of earlier researchers (Singh and Dhillon, 2006; Musmade et al., 2008; Tomar et al., 2008; Rad et al., 2010) in muskmelon. In general, the genotypes grouped together in one cluster are less divergent than those which are placed in a different cluster. Further, higher intracluster distance indicates high degree of divergence within that cluster. The maximum intercluster distance was observed between cluster I and VI followed by cluster IV and cluster VI and cluster II and cluster VI, indicating wider genetic diversity among the genotypes included in these groups. Selection of parents from these diverse clusters for hybridization programme would help in achieving novel recombinants. Similar observations were reported in muskmelon by Singh and Lal (2000), More and Seshadri (2002), Krishnaprasad (2004) and Singh and Dhillon (2006). Genotypically distant parents are expected to exert high heterosis (Moll et al., 1962; Ramanujam et al., 1974). In general, crosses involving parents belonging to most divergent clusters are expected to give maximum heterosis and create wide variability in genetic architecture. However, the divergent clusters need not be of desirably high or low mean values for all the growth, earliness and fruit traits. Hence, apart from selecting genotypes from the clusters which have high inter cluster distance for hybridization, one can also think of selecting parents based on extent of genetic divergence in respect to a particular character of interest.

The germplasm utilized for the present study consisted of three solitary clusters (cluster III, $\mathrm{V}$ and VI). The clusters III (RNMM-31), V (RNMM-32) and VI (RNMM-3) displayed zero intracluster distance could be attributed to limited gene exchange or selection practices among the genotypes for diverse characters. The genotypes in these three solitary clusters namely RNMM-31, RNMM32 and RNMM-3, being diverge from others may serve as potential parents for breeding programmes. They indicate their independent identity and importance due to various unique characters possessed by them. The genotype 
RNKM-31 with lowest number of days to appearance of staminate and pistillate flowers and lowest number of days to first and last fruit harvest was found to be highly precocious. The genotype RNKM-32 longest vines and highest number of fruits per vine was found to be highly vigorous and prolific. The genotype RNMM-3 with highest number of branches per vine, highest fruit weight and highest fruit yield per vine was found to be high yielding. These unique genotypes can be utilised in crop improvement programme as donor parents for improving the respective characters. Mahalanobis $\mathrm{D}^{2}$ statistics was found to be a useful tool to assess the relative contribution of different characters to the total divergence both inter and intracluster levels. In general, the characters responsible for discrimination between populations can narrow down the problem of selecting divergent parents for breeding programme. From the results of percent contribution of individual characters towards divergence, it is evident that there was greater diversity in the material under study for total soluble solids, days to appearance of first staminate flower, average fruit weight, fruit cavity length offering ample scope for selection and choice of desirable parents for breeding programme. Amongst the yield contributing characters, the characters days to appearance of first staminate flower, average fruit weight, fruit cavity length were the major contributors towards divergence. The present findings are in consonance with those of Tomar et al., (2008), who also noticed highest contribution of total soluble solids towards diversity in 50 genotypes of muskmelon and of Yadav et al., (2005), who also noticed least contribution of fruit yield towards diversity in 30 accessions of muskmelon. De et al., (1988) opined that traits contributing maximum towards the $\mathrm{D}^{2}$ values need to be given more emphasis for deciding the clusters to be taken for the purpose of choice of parents for hybridization. The characters that predominantly contributed to divergence in this study like days to appearance of first staminate flower, average fruit weight also happen to be the main components of yield. The results of the present study point out a positive contribution of genetic divergence and yield components; this can be of considerable help in selecting for yield and other economic traits. It can be concluded that there was more divergence for these characters offering greater scope while making selection of horticulturally superior genotypes of okra.

Multivariate analysis considering 18 morphological traits following Mahalanobis $\mathrm{D}^{2}$ statistic revealed good diversity among 35 genotypes of muskmelon, which were grouped into six distinct clusters. The genotypes of diverse clusters I and VI, clusters IV and VI and clusters II and IV could be used in hybridization programme either to produce highly heterotic $F_{1} s$ or to generate wide range of transgressive segregants in population to develop high yielding varieties of muskmelon. The characters total soluble solids, seed yield, days to appearance of first staminate flower, average fruit weight contributed maximum towards divergence among the muskmelon genotypes.

\section{Acknowledgements}

The authors are highly thankful to the National Bureau of Plant Genetic Resources Regional Station, Hyderabad for providing the germplasm for the present study.

\section{References}

Arunachalam, V. 1981. Genetic distance in plant breeding. Indian J. Genet., 41: 226-236.

Choudhary, H. and Ram, H. H. 2003. Genetic diversity studies in muskmelon. Ann. Agric. Res., 24(2): 345-349. 
De, R.N., Seetharaman, R., Sinha, M. T. and Banerjee, S. P. 1988. Genetic divergence in rice. Indian J. Genet., 48: 189-194.

FAO. 1997.Quarterly bulletin of statistics. Food and Agricultural Organization of United Nations, Rome pp. 66-70.

Genetic divergence in long melon (Cucumismelo var. utillissimus). Progr. Agric., 5(1/2): 50-52.

Joshi, A. B. and Dhawan, N. L. 1966. Genetic improvement of yield with special reference to self-fertilizing crops. Indian J. Genet., 26: 101-113.

Krishnaprasad, V. S. R., Pitchaimuthu, M. and Dutta, O. P. 2004. Variation, diversity pattern and choice of parental selection in musk melon (Cucumismelo L.) improvement. Indian J. Hort., 61(4): 319-322.

Luan, F., Sheng, Y., Wang, Y. and Staub, J. E. 2010. Performance of melon hybrids derived from parents of diverse geographic origins. Euphytica, 173: 1-16.

Mahalonobis, P.C. 1936. On the generalized distance in statistics. In: Proc. Nat. Acad. Sci. India, 2: 49-55.

Moll, R. H., Salhwana, W. S. and Robinson, H. S. 1962. Heterosis and genetic diversity in variety crosses in maize. Crop Sci., 2: 197-198.

More, T. A. and Seshadri, V. S. 2002. Studies on genetic divergence in muskmelon (Cucumismelo L.). J. Maharashtra Agric. Univ., 27(2): 127-131.

Murthy, B. R. and Arunachalam, V. 1960. The nature of divergence in relation to breeding system in some crop plants.
Indian J. Genet., 26A: 188-198.

Musmade, A. M., Torkadi, S. S., Patil, R. S. and Asane, G. B. 2008. Genetic divergence in muskmelon

(Cucumis melo L.). J. Maharashtra Agric. Univ., 33(1): 133-135.

Rad, M. R. N., Allahdoo, M. and Fanaei, H. R. 2010. Study of some yield traits relationship in melon (Cucumismelo L) germplasm gene bank of Iran by correlation and factor analysis. Trakia J. Sci., 8(1): 27-32.

Ramanujam, S., Tiwary, A. S. and Mehra, R. B. 1974. Genetic divergence and hybrid performance in mungbean. Theor. Appl. Genet., 44(5): 211-214.

Rao, C. R. 1952. Advanced statistical methods in biometrical research. John Wiley and Sons, New York.

Singh, G. and Dhillon, N.P.S. 2006. Genetic divergence in muskmelon germplasm. Haryana J. Hort. Sci., 35(3/4): 340341.

Singh, R. K. and Chaudhary, B. D. 1985. Biometrical methods in quantitative genetic analysis. Kalyani Publishers, Ludhiana, India. 30-34 pp.

Singh, S. and Lal, T. 2000. Assessment of genetic divergence in melon (Cucumismelo L.). J. Res.: Punjab Agric. Univ., 37(1-2): 36-41.

Tomar, R. S., Kulkarni, G. U. and Kakade, D. K. 2008. Genetic analysis in muskmelon (Cucumismelo L.). J. Hortic. Sci., 3(2): 112-118.

Yadav, J. R., Gaurav, M., Shukla, N. S., Singh, H. C., Singh, B. and Srivastava, J.P. 2005.

\section{How to cite this article:}

Praveen Kumar Reddy, B., Hameedunnisa Begum, Neelum Sunil and Thirupathi Reddy, M. 2017. Genetic Divergence Analysis in Muskmelon (Cucumis melo L.). Int.J.Curr.Microbiol.App.Sci. 6(6): 2251-2260. doi: https://doi.org/10.20546/ijcmas.2017.606.267 